\title{
A rare pathology that caused high-level intestinal obstruction: Left paraduodenal hernia
}

\author{
Muharrem Öztaş, Mehmet Fatih Can, Erkan Öztürk, Gökhan Yağcı
}

ABSTRACT

Department of General Surgery, Gülhane Military Medical Academy, Ankara, Turkey

This case presented as poster the $47^{\text {th }}$ Annual Congress of ESSR (European Society for Surgical Research), 6-9 june 2012.

\section{Address for Correspondence} Dr. Muharrem Öztaş Department of General Surgery, Gülhane Military Medical Academy, Ankara, Turkey Phone.: +90 4862181000 e-mail:

mmoztas@hotmail.com

Received: 19.05 .2012 Accepted: 12.11 .2012 Online Available Date: 09.07.2013

OCopyright 2013 by Turkish Surgical Association

Available online at www.ulusalcerrahidergisi.org
The aim of this report is to assess clinical findings and surgical treatment of left paraduodenal hernia, which is an unusual type of internal herniation, in light of the literature. The diagnosis and treatment course of a 42-year-old male patient with findings of intestinal obstruction was assessed and presented together with literature search. The patient underwent surgery with a preliminary diagnosis of intestinal obstruction and the definitive diagnosis of internal herniation was made intraoperatively. Nearly two-thirds of the small intestine was found to be herniated into the retroperitoneal space from the left paraduodenal region. Small bowel loops were pulled out of the hernia sac and anatomically positioned in the intraperitoneal area. The hernia sac was repaired primarily. The patient was discharged on the fourth postoperative day, uneventfully. Left paraduodenal hernia should be considered as a part of differential diagnosis in patients who have recurring abdominal pain episodes accompanied by symptoms suggestive of intestinal obstruction. Timely diagnosis is important to prevent complications. Reduction of hernia content followed by primary repair of the defect appears to be a safe and effective treatment.

Key Words: Paraduodenal hernia, internal hernia, intestinal obstruction

\section{INTRODUCTION}

Internal herniation is defined as herniation of the small intestine through a mesenteric defect within the abdominal cavity (1). Internal hernia is a rare cause of acute abdomen, and can lead to intestinal obstruction and ischemia if not diagnosed and treated in time $(2,3)$. Internal herniation constitutes 0.6 to $5.8 \%$ of patients with intestinal obstruction (4-6). Paraduonenal hernia is the cause of approximately $50 \%$ of internal hernias and is responsible for approximately $1 \%$ of all small bowel obstructions $(2,3$, 5-9). Transmesenteric hernia, foramen of Winslow hernia, paracecal hernia and transomental hernia are other types of congenital internal hernias (6). Paraduodenal hernia is observed 3 times more in the left than in the right $(3,5-7,9,10)$. It is most commonly seen in the 4 th and 6 th decades $(3,5)$. Its occurrence in men is three times more common than in women $(3,5,6,9)$. During a lifetime, half of the cases carry a risk of intestinal obstruction or strangulation, whereas the other half can remain silent (5). Herein we shared our experience of a patient operated on for a left paraduodenal hernia.

\section{CASE PRESENTATION}

A 42-year-old male patient who presented in the emergency department with abdominal pain, nausea and vomiting was hospitalized with a preliminary diagnosis of bowel obstruction. His past medical history was insignificant except an appendectomy. However, the patient stated that he had been experiencing similar complaints from time to time, that it spontaneously resolved since childhood, and that he was not evaluated for this complaint. On arrival, the patient's blood pressure was $125 / 80 \mathrm{mmHg}$, with a pulse rate of $74 / \mathrm{min}$ and temperature of 36.7 degrees. On physical examination, there was a moderately asymmetric distention, which was especially evident in the left quadrants. All quadrants were tender on palpation, while there was no rebound tenderness or guarding. A nasogastric tube decompression was provided and intravenous fluid replacement was planned.

The leukocyte count was 11700 and other biochemical values were within normal limits. A plain abdominal X-ray localized several air-fluid levels in the left upper quadrant (Figure 1). Computed tomography showed clustered bowel loops in the same localization (Figure 2). The patient was followed up for about 12 hours and was then operated due to increase in abdominal distension and development of signs of peritoneal irritation. A laparoscopic exploration was done through a subumbilical $1 \mathrm{~cm}$ incision. On exploration, small bowel loops (proximal jejunum and ileum) were not observed except the distal ileum. The sigmoid colon was collapsed. The transverse colon and omentum were pushed toward the epigastric region, and the mesentery of the left colon and sigmoid colon toward the anterior abdominal 


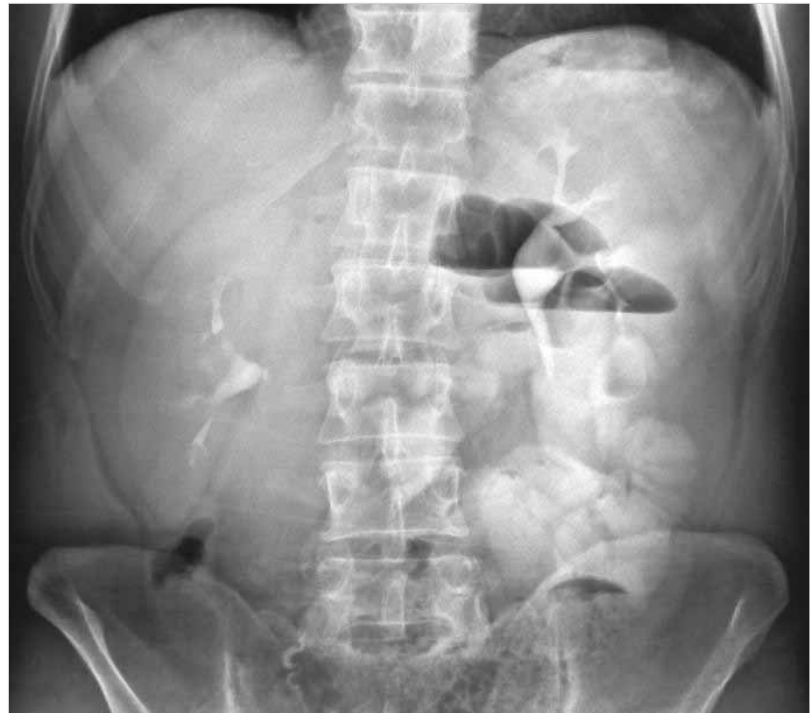

Figure 1. Air-fluid levels in the left upper quadrant in plain abdominal X-ray

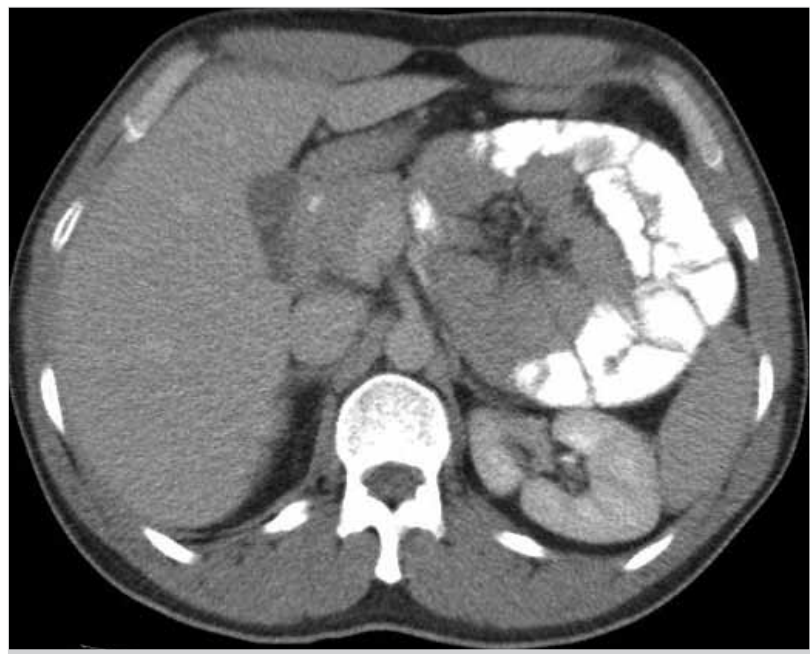

Figure 2. Bowel loops clustered in the left upper abdomen on abdominal computed tomography

wall. The ileal loop was grasped from the proximal part and withdrawn, but it could not be mobilized and it was decided to convert to laparotomy. At laparotomy, all bowel loops except the terminal ileum were observed to have herniated posteriorly through an opening in the left paraduodenal region and the mesentery was partially rotated (Figure 3). Intestinal loops were reduced by manual traction. The vascular supply of the small intestine was damaged in some segments but they all returned to their normal color after detorsion and warming (Figure 4). The defect was primarily repaired by multifilament, absorbable 3-0 sutures and the operation was completed. The patient's postoperative course was uneventful and he was discharged on the fourth postoperative day. He did not have any complaints during the 1-year postoperative follow-up.

\section{DISCUSSION}

The most common theory regarding development of paraduodenal hernias was described by Andrews in 1923, stating that due to a midgut rotation abnormality during the $5^{\text {th }}$ and $11^{\text {th }}$ weeks of embryologic development bowels are shifted

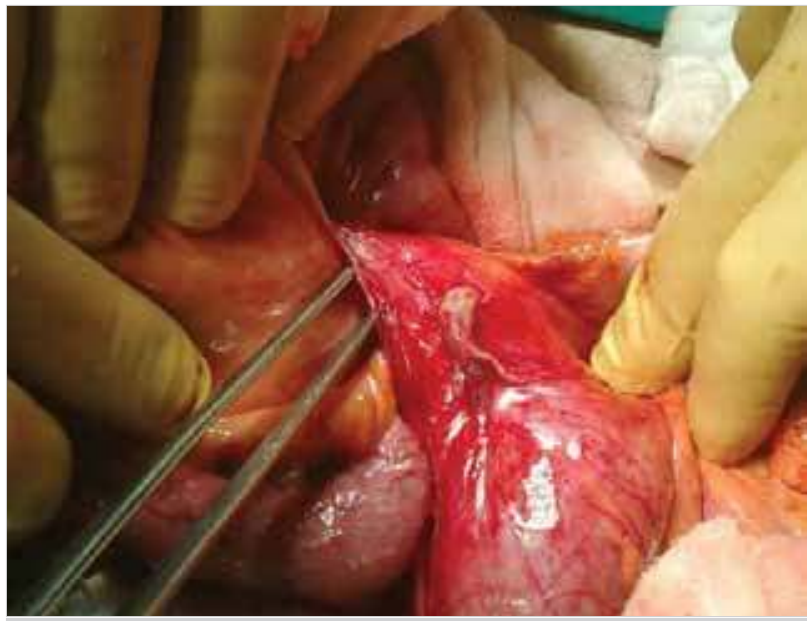

Figure 3. Left paraduodenal defect at laparotomy

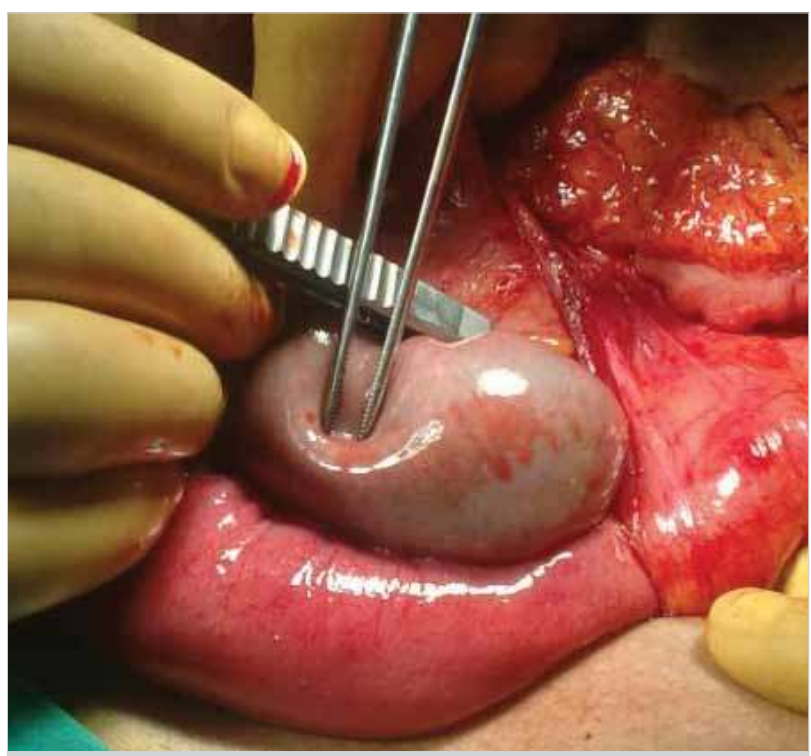

Figure 4. View of the defect and small bowel wiht partial impairment of vascular supply (before warming)

between the mesentery and posterior abdominal wall, in other words they are caused by congenital peritoneal anomalies or intestinal rotation anomalies $(2-7,9,10)$. Defect in fusion of the mesentery and posterior parietal peritoneum creates a potential hernia orifice $(2,4)$. In left paraduodenal hernias, the jejunal loops are herniated through this opening located to the left of the ligament of Treitz (4). This left paraduodenal fossa has been described by Landzert for the first time in 1871, it is located to the lateral of the fourth part of duodenum , and posterior to the inferior mesenteric vein and the left colic artery $(6,10,11)$. Treitz reported that three factors were required for the formation of a paraduodenal hernia (11). These factors are the paraduodenal fossa, a hernia sac with its front boundary formed by the inferior mesenteric vein and small bowels that are capable of sufficient mobilization to enter this fossa. Increased intraabdominal pressure causes the beginning of herniation (11). The hernia content consists of small bowel loops. It does not include the colon and omental tissue. The hernia sac can consist of only a few centimeters of intestinal loops, or all the small intestine (10). Similarly in our patient, the hernia contents contained only the small bowel loops. Bowel 
loops except the distal ileum were within the hernia sac. Clinically, in majority of the patients, episodes of partial or complete intestinal obstruction are observed $(12,13)$. They may sometimes be asymptomatic and can be incidentally identified by imaging studies performed for other reasons, during laparotomy or autopsy series $(2,6,9,10)$. Clinical symptoms are in the form of recurrent cramp-like abdominal pain, intestinal obstruction due to torsion, nausea, vomiting and abdominal distention $(3,5)$. Tong et al. (9) evaluated 32 cases, and they reported that chronic symptoms are seen in $69 \%$ of patients and that $66 \%$ of patients present with acute obstruction or strangulation. In our patient, there was a similar clinical presentation. She had suffered from intermittent abdominal pain since childhood. The diagnosis is quite difficult due to the pathology's being congenital, not related to previous surgery and nonspecific findings on physical examination (3, 4 , 7). On physical examination, abdominal distention, especially in the left upper quadrant, can be detected (10). Sometimes a firm mass can be palpable in this region (10). Imaging plays an important role in diagnosis. Plain abdominal X-rays show displacement of bowel loops to an area and air -fluid levels $(5-7,9)$. Visualization of dilated bowel loops clustered between the stomach, pancreas and spleen is diagnostic and typically extension of the vascular structures supplying the herniated loops into the hernia sac can be monitored $(2,3,5$, $7,9)$. In our case, physical examination and radiologic findings described in the literature were observed. While there was asymmetric abdominal distention in the left upper quadrant, abdominal X-ray showed air-fluid levels in the same region and computed tomography revealed bowel loops clustered in that area (Figure 1,2). Biochemical parameters may vary according to the presence of ischemia or necrosis in herniated bowel loops. Patients should be treated surgically even if they were diagnosed incidentally, because in $50 \%$ of these patients there is a possibility of developing intestinal obstruction at a given time $(3,5,6,14)$. Elective cases can be treated by laparoscopy $(2,15-17)$. Uematsu et al. (18) repaired a left paraduodenal hernia that spontaneously reduced electively by laparoscopy. Fink et al. (19) reported successful laparoscopic repair in an incidentally diagnosed patient, and Fukunaga et al. (16) in an incarcerated hernia. Delay in diagnosis could result in acute intestinal necrosis. In our case, vascularization of intestinal loops was impaired but they were not necrotic. Probably a wide resection of bowel loops would be inevitable if the decision to operate was delayed. Mortality rate due to complications in paraduonenal hernias is about $20 \%$, but especially in cases of strangulation, with delay in diagnosis and treatment mortality rates as high as $50 \%$ have been reported $(6,9)$. The mainstay of treatment is the reduction of herniated bowel loops and primary repair of the defect $(2,3,5,7,9)$. During surgery extra attention should be paid to the inferior mesenteric vein coursing upwards at the free edge of the hernia sac and the left colic artery coursing on the anterior wall of the $\operatorname{sac}(3,5,9)$. However, in cases where the hernia neck is narrow, where there are adhesions between bowel loops and in the presence of severe distension, the inferior mesenteric vessels can be cut or the hernia sac can be reached by an incision through the avascular plane to the left of the inferior mesenteric vein $(3,5,9)$.

\section{CONCLUSION}

Internal herniation should be considered in the differential diagnosis of intestinal obstruction, especially in patients without previous abdominal surgery who complain of recurrent mechanical bowel obstruction episodes. Timely diagnosis and surgical treatment is of utmost importance in terms of prevention of complications like intestinal ischemia and necrosis, which may result in morbidity and sometimes mortality.

Informed Consent: Written informed consent was obtained from the patient who participated in this case report.

Peer-review: Externally peer-reviewed.

Author Contributions: Concept - G.Y., E.Ö.; Design - G.Y., E.Ö.; Data Collection and/or Processing - M.F.C., M.Ö.; Analysis and/or Interpretation - G.Y., E.Ö.; Writer - M.Ö., M.F.C.

Acknowledgements: The authors thank Dr. Yusuf Peker and Dr. Ramazan Yıldız for their contributions.

Conflict of Interest: No conflict of interest was declared by the authors.

Financial Disclosure: The authors declared that this study has received no financial support.

\section{REFERENCES}

1. Blachar A, Federle MP. Internal hernia: an increasingly common cause of small bowel obstruction. Semin Ultrasound CT MR 2002; 23: 174-183. [CrossRef]

2. Shoji T, Nishiyama R, Oba K, Azuma M. Successfully treated with laparoscopic surgery: a case report. Case Rep Gastroenterol 2007; 1: 71-76. [CrossRef]

3. Huang YM, Chou AS, Wu YK, Wu CC, Lee MC, Chen HT, et al. Left paraduodenal hernia presenting as recurrent small bowel obstruction. World J Gastroenterol 2005; 11: 6557-6559.

4. Fernández-Rey C.L, Martínez-Álvarez C, Concejo-Cutoli P. Acute abdomen secondary to left paraduodenal hernia: diagnostic by multislice computer tomography. Rev Esp Enferm Dig 2011; 103: 38-39. [CrossRef]

5. Şen M, Inan A, Dener C, Bozer M. Paraduodenal internal hernia: clinical analysis based on two cases. Ulus Travma Acil Cerrahi Derg 2007; 13: 232-236.

6. Manji R, Warnock GL. Left paraduodenal hernia: an unusual cause of small-bowel obstruction. Canadian Journal of Surgery 2001; 44: 455-457.

7. Acu R, Ökten S, Küçükay F, Tunç B, Kalkan IH, Ölçer T. Left paraduodenal hernia: Multisliced computered tomography findings. Akademik Gastroenteroloji Dergisi 2010; 9: 38-40.

8. Berardi RS, lowa DM. Paraduodenal hernias. Surg Gynecol Obstet 1981; 152: 99-110.

9. Tong RSK, Sengupta S, Tjandra JJ. Left paraduodenal hernia: case report and review of the literature. ANZ J Surg 2002; 72: 69-71. [CrossRef]

10. Murray HOL. Left paraduodenal hernia. Canad MAJ 1955; 72: 263-267.

11. Desjardins AU. Left paraduodenal hernia. Ann Surg 1918; 67: 195201. [CrossRef]

12. Brigham RA, d'avis JC. Paraduodenal hernia. In: Nyhus LM, Condon RE, editors. Hernia. 3rd ed. Philadelphia: Lippincott; 1989.p.481-486.

13. Khan MA, Lo AY, Vande Meale DM. Paraduodenal herni. Am Surg 1998; 64: 1218-1222. 
14. Newsom BD, Kukora JS. Congenital and acquired internal hernias: unusual causes of small bowel obstruction. Am J Surg 1986; 152 279-285. [CrossRef]

15. Osadchy A, Weisenberg N, Wiener Y, Shapiro-Feinberg M, Zissin R. Small bowel obstruction related to left-side paraduodenal hernia: CT findings. Abdom Imaging 2005; 30: 53-55. [CrossRef]

16. Fukunaga $M$, Kidokoro A, Iba T, Sugiyama K, Fukunaga T, Nagakari $\mathrm{K}$, et al. Laparoscopic surgery for left paraduodenal hernia. J Laparoendosc Adv Surg Tech 2004; 14: 111-114. [CrossRef]
17. Antedomenico E, Singh NN, Zagorski SM, Dwyer K, Chung MH. Laparoscopic repair of a right paraduodenal hernia. Surg Endosc 2004; 18: 165-166. [CrossRef]

18. Uematsu T, Kitamura H, Iwase M, Yamashita K, Ogura H, Nakamuka $\mathrm{T}$, et al. Laparoscopic repair of a paraduodenal hernia. Surg Endosc 1998; 12: 50-52. [CrossRef]

19. Finck CM, Barker S, Simon H, Marx W. A novel diagnosis of left paraduodenal hernia through laparoscopy. Surg Endosc 2000; 14: 87. 